\title{
COMPARATIVE EVALUATION OF 0.5\% ROPIVACAINE AND 0.5\% BUPIVACAINE IN COMBINED FEMORAL AND LATERAL FEMORAL CUTANEOUS NERVE BLOCK FOR POST OPERATIVE ANALGESIA IN KNEE AND ABOVE KNEE ORTHOPAEDIC SURGERIES UNDER SPINAL ANAESTHESIA
}

\author{
Dilip Kothari¹, Sukhnandan Singh Tomar², Bhanu Choudhary33, Mehreen Meer ${ }^{4}$, Srivathsan $J^{5}$
}

1 Professor, Department of Anaesthesiology, Gajra Raja Medical College, Gwalior, Madhya Pradesh, India.

${ }_{2}^{2}$ Postgraduate Student, Department of Anaesthesiology, Gajra Raja Medical College, Gwalior, Madhya Pradesh, India.

3Professor and HOD, Department of Anaesthesiology, Gajra Raja Medical College, Gwalior, Madhya Pradesh, India.

${ }_{4}^{4}$ Postgraduate Student, Department of Anaesthesiology, Gajra Raja Medical College, Gwalior, Madhya Pradesh, India.

${ }^{5}$ Postgraduate Student, Department of Anaesthesiology, Gajra Raja Medical College, Gwalior, Madhya Pradesh, India.

\section{BACKGROUND}

\section{ABSTRACT}

Femoral Nerve Block (FNB) and Lateral Femoral Cutaneous Nerve Block (LFCNB) are easy to perform, have high success rates, have fewer complications and have significant clinical applicability for post-operative pain management in surgeries on the anterior thigh, knee and quadriceps tendon repair. We compared the efficacy of $0.5 \%$ Ropivacaine and $0.5 \%$ Bupivacaine in combined femoral and lateral femoral cutaneous nerve block on the duration of postoperative analgesia in knee and above knee surgeries.

\section{MATERIALS AND METHODS}

90 patients of ASA grade I and II who underwent knee and above knee surgeries of lower limb were included in this study. These patients were divided in to three groups $(\mathrm{n}=30$ each) according to the study drugs. Group N (Normal Saline), Group $\mathrm{R}(0.5 \%$ Ropivacaine), and Group B (0.5\% Bupivacaine). Each patient received a fixed volume of study drugs: $15 \mathrm{ml}$ for FNB and $8 \mathrm{ml}$ for LFCNB. The patients were observed for Time of Onset of Analgesia (TOA), Duration of Analgesia (DOA), Assessment of Severity and Time of Post-Operative Pain.

\section{RESULTS}

Onset of action was faster with Ropivacaine as compared to Bupivacaine $(\mathrm{p}=0.001)$ (Group $\mathrm{R}<\mathrm{B}<\mathrm{N}$ ). Duration of analgesia was longer (Group $\mathrm{R}>\mathrm{B}>\mathrm{N}$ ) in Ropivacaine group than Bupivacaine ( $\mathrm{p}=0.001)$. VAS $>3$ was observed at $7.13 \pm 1.01 \mathrm{hrs}$., $15.06 \pm 1.72 \mathrm{hrs}$. and $11.33 \pm 1.52$ hrs. in group N, $R$ and $B$ respectively $(p<0.05)$.

\section{CONCLUSION}

Combined Femoral Nerve Block and Lateral Femoral Cutaneous Nerve Block with Ropivacaine provides early onset, prolonged duration and better relief in post-operative pain with minimal adverse effects as compared to Bupivacaine in knee and above knee surgeries.

\section{KEY WORDS}

Bupivacaine, Femoral Nerve, Lateral Femoral Cutaneous Nerve, Postoperative Pain, Ropivacaine, Spinal Anaesthesia.

HOW TO CITE THIS ARTICLE: Kothari D, Tomar SS, Choudhary B, et al. Comparative evaluation of 0.5\% ropivacaine and 0.5\% bupivacaine in combined femoral and lateral femoral cutaneous nerve block for post-operative analgesia in knee and above knee orthopaedic surgeries under spinal anaesthesia. J. Evolution Med. Dent. Sci. 2019;8(06):369-372, D0I: 10.14260/jemds/2019/81

\section{BACKGROUND}

In modern anaesthesia practice, an increasing trend in peripheral nerve blocks for both intra operative and postoperative management of pain has been observed. Introduction of new devices like Peripheral Nerve Stimulator and Ultra Sonography have been very useful in the accurate localisation of nerves and deposition of local anaesthetics to give early onset and prolonged effect of block thus providing good pain relief with less side effects and early mobilisation in postoperative period. ${ }^{1}$

'Financial or Other Competing Interest': None.

Submission 28-12-2018, Peer Review 29-01-2019,

Acceptance 04-02-2019, Published 11-02-2019.

Corresponding Author:

Dr. Sukhnandan Singh Tomar,

\#23-C, Purushottam Vihar Colony,

Gola Ka Mindir, Bhind Road,

Gwailor-474005, Madhya Pradesh, India.

E-mail: sukhnandansinghtomar88@gmail.com

DOI: $10.14260 /$ jemds $/ 2019 / 81$

\section{(c) (i) $\$($}

Femoral nerve block (FNB) combined with Lateral Femoral Cutaneous Nerve block (LFCNB)is an easy to learn technique with high success rate, increased safety profile and a significant clinical applicability for post-operative pain management in surgeries on the knee and above knee. ${ }^{2}$

Ropivacaine structurally analogue local Anaesthetic drug to Bupivacaine with lesser toxicity and prolonged sensory and motor block effect has been in use for nerve blocks both single shot and continuous infusion. ${ }^{3}$ On literature search we could not find many studies comparing Ropivacaine and Bupivacaine in combined FNB and LFCNB for post-operative pain relief in surgeries on knee and above knee area. Hence, we decided to do comparative evaluation of $0.5 \%$ Ropivacaine and $0.5 \%$ Bupivacaine in combined femoral and lateral femoral cutaneous nerve block for post-operative analgesia in knee and above knee orthopaedic surgeries under spinal anaesthesia.

\section{MATERIALS AND METHODS}

The randomised control trial study conducted in 90 patients (ASA Grade I \& II) who underwent knee and above knee 
orthopaedic surgeries under spinal anaesthesia in the G.R. Medical college \& J. A. Group of Hospitals, Gwalior (M. P). After obtaining permission from institutional ethics committee, patients between the age group 18 to 60 years of either sex and weighing between 50-90 Kgs. were enrolled in this study. Exclusion criteria were Patient's refusal, uncooperative patients, infection at site of injection, pregnancy and lactating women, patient with history of allergy to local anaesthetic drugs, moderate to severe systemic, metabolic disease, and bleeding diathesis.

We have used purposive (Non-probability) sampling for selection of subjects and on the convenience basis, we have decided the subjects for our clinical studies and simple random sampling (Every member of the population has equal chances of getting selected) done of patients. Since the duration of the study was few months. The sample size taken for conveniences.

All 90 patients included in the study were randomly divided into three groups according to study drugs as follows-

- Group N (n=30): $15 \mathrm{ml}$ Normal saline (NS) for FNB and 8 $\mathrm{ml}$ of NS for LFCNB.

- $\quad$ Group R (n=30) $15 \mathrm{ml}$ of 0.5\% Ropivacaine for FNB and $8 \mathrm{ml}$ of $0.5 \%$ Ropivacaine for LFCNB.

- Group B (n=30): $15 \mathrm{ml}$ of 0.5\% Bupivacaine for FNB and $8 \mathrm{ml}$ of $0.5 \%$ Bupivacaine for LFCNB.

\section{Procedure of Block}

- Preparation of Patient: Upon arrival of the patient in operating room, all the baseline vital parameters including Heart Rate (HR), Blood Pressure (BP) and Oxygen saturation $\left(\mathrm{SpO}_{2}\right)$ were recorded. Thereafter 18 SWG cannula was inserted and $500 \mathrm{ml}$ of RL was infused within 20 minutes as preloading.

- Under all aseptic precautions cleaning, painting \& draping was done in inguinal area of operative lower limb in supine position. With the patient supine, anatomical landmarks of the femoral nerve and lateral femoral cutaneous nerve was identified at the inguinal crease $1 \mathrm{~cm}$ lateral to the pulsations of the femoral artery and $2 \mathrm{~cm}$ medial and inferior to the anterior superior iliac spine, respectively. These points were infiltrated with $0.5 \mathrm{ml} 1 \%$ lignocaine subcutaneously. Femoral nerve was identified with a 22 gauge, $50 \mathrm{~mm}$, short-bevelled, Teflon-coated, unipolar needle (Stimuplex ${ }^{\mathrm{TM}}$ ) as peripheral quadriceps femoris contractions and to \& fro patellar movement at current strength of $<0.5 \mathrm{~mA}$ with help of peripheral nerve stimulator (Plexygon, Vygon) and after negative aspiration test dose of LA (1 mL) was administered to check the loss of muscle twitches. Then full dose of study drugs was injected gradually after repeated negative aspiration to avoid intravascular injection of local anaesthetic drug.

- For LFCNB, a point $2 \mathrm{~cm}$ medial and $2 \mathrm{~cm}$ distal to the anterior superior iliac spine was identified. A short 22gauge block Stimuplex ${ }^{\mathrm{TM}}$ needle was inserted and directed laterally, to observe a "pop" as it passes through the fascia lata. A field block was performed with $8 \mathrm{~mL}$ of study drugs, deposited above and below the fascia after repeated negative aspiration.
- After successful block all the patients were operated for various surgeries on knee and above the knee under spinal anaesthesia using 0.5\% Bupivacaine heavy in supine position. Haemodynamic parameters like PR, BP and SpO2 were monitored and maintained within normal limits. After completion of operations all the patients were shifted to post-operative anaesthesia care room for further observations.

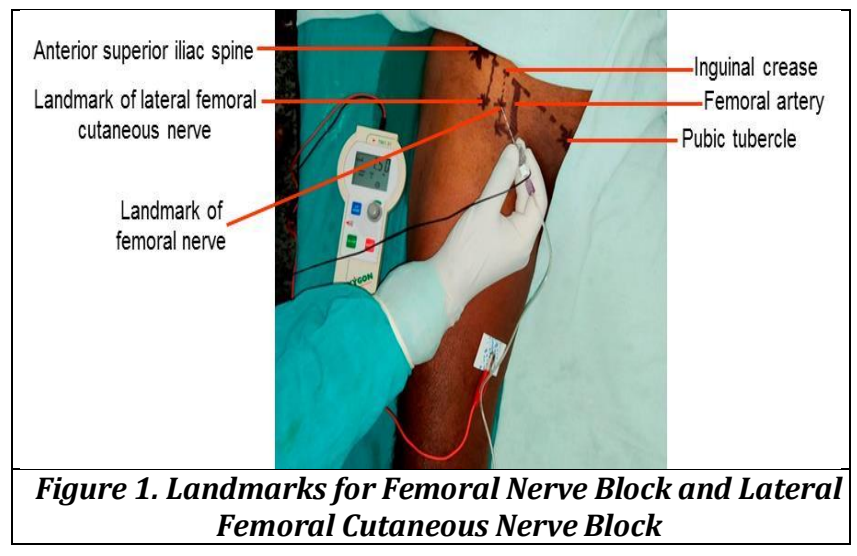

\section{Parameters of Study}

Time for onset of analgesia (Time between end of injection of study drug to complete loss of pin prick), Duration of analgesia (Time interval between TOA and first complaint of pain in post-operative period), Time for Rescue analgesia (VAS>3) were noted.

Assessment and recording of Haemodynamic parameters like Pulse rate (PR), Systolic Blood Pressure (SBP), Diastolic Blood Pressure (DB)), Mean Blood Pressure (MAP) were monitored and maintained within normal limits throughout the study period as per minimum standard monitoring protocol.

Observation and recording of side effects and complications of the study drugs and technique were done if occurred.

\section{Statistical Analysis}

For statistical significance, with a power of $80 \%$ and a level of significance of $5 \%$, a study population of group was needed to evaluate $>1$-h difference in demand of analgesia among groups. Quantitative data analysis was done by ANOVA, whereas qualitative variables were subjected to Chi-square tests all data were presented as mean \pm standard deviation (SD). $\mathrm{P}<0.05$ was considered statistically significant.

\section{RESULTS}

Demographic data regarding the Mean \pm SD of Age in years, and Weight in Kilograms and Sex were comparable in all the study groups. ( $\mathrm{p}>0.05)$

As shown in Table 2, early Time for onset of Analgesia (in seconds) was observed in group $\mathrm{R}$ as compared to group $\mathrm{B}$ $(\mathrm{p}<0.000)$. No value of TOA was recorded in Group N as we used Normal saline. Duration of analgesia was more prolonged in group $\mathrm{R}$ as compared to other study groups $(\mathrm{R}>$ $\mathrm{B}>\mathrm{N} ; \mathrm{p}<0.000$ ). VAS $>3$ was observed earliest in Group $\mathrm{N}$ as compared to group B and group $\mathrm{R}(\mathrm{p}<0.000)$.

No major side effects or complication were observed in this study. Incidence of post-operative nausea, vomiting and 
shivering were higher in group $\mathrm{N}$ as compared to other study groups.

\begin{tabular}{|c|c|c|c|c|}
\hline $\begin{array}{c}\text { Demographic } \\
\text { Parameter }\end{array}$ & $\begin{array}{c}\text { Group N } \\
(\mathbf{n = 3 0 )}\end{array}$ & $\begin{array}{c}\text { Group R } \\
(\mathbf{n = 3 0})\end{array}$ & $\begin{array}{c}\text { Group B } \\
(\mathbf{n}=\mathbf{3 0})\end{array}$ & p Value \\
\hline Age (Yrs.) & $\begin{array}{c}38.36 \pm \\
13.30\end{array}$ & $\begin{array}{c}43.33 \pm \\
14.28\end{array}$ & $\begin{array}{c}40.2 \pm \\
14.72\end{array}$ & $0.38^{*}$ \\
\hline Weight & $64.33 \pm$ & $64.16 \pm$ & $64.93 \pm$ & $0.83^{*}$ \\
(in Kgs.) & 5.97 & 5.42 & 5.29 & \\
\hline \multicolumn{4}{|r|}{ Table 1. Demographic Profile (Mean \pm SD) } \\
\hline p $>0.05=$ Statistically not significant \\
\hline
\end{tabular}

\begin{tabular}{|c|c|c|c|c|}
\hline Parameter & $\begin{array}{c}\text { Group N } \\
(\mathbf{n = 3 0 )}\end{array}$ & $\begin{array}{c}\text { Group R } \\
(\mathbf{n = 3 0 )}\end{array}$ & $\begin{array}{c}\text { Group B } \\
(\mathbf{n = 3 0})\end{array}$ & p Value \\
\hline TOA (sec) & - & $44 \pm 10.03$ & $73.66 \pm 12.45$ & $0.000^{* *}$ \\
\hline DOA (hr.) & $5.86 \pm 0.73$ & $10.53 \pm 1.96$ & $7.06 \pm 1.01$ & $0.000^{* *}$ \\
\hline TRA (hr.) & $7.13 \pm 1.01$ & $15.06 \pm 1.72$ & $11.33 \pm 1.52$ & $0.000^{* *}$ \\
\hline
\end{tabular}

Table 2. Time for Onset, Duration and Rescue of Analgesia (Mean \pm SD)

${ }^{* *} \mathrm{p}<0.01=$ Statistically Highly significant

\begin{tabular}{|c|c|c|c|c|c|c|c|}
\hline \multirow[b]{2}{*}{$\begin{array}{c}\text { Side } \\
\text { Effect }\end{array}$} & \multicolumn{2}{|c|}{ Group N } & \multicolumn{2}{|c|}{ Group R } & \multicolumn{2}{|c|}{ Group B } & \multirow{2}{*}{\begin{tabular}{|c} 
Value \\
$\mathbf{p}$ \\
Value \\
\end{tabular}} \\
\hline & \begin{tabular}{|c|} 
No. of \\
Patients \\
\end{tabular} & (\%) & \begin{tabular}{|c|} 
No. of \\
Patients \\
\end{tabular} & $\%$ & $\begin{array}{c}\text { No. of } \\
\text { Patients } \\
\end{array}$ & (\%) & \\
\hline & 08 & 26.66 & 04 & 13.33 & 04 & 13.33 & 0.024 \\
\hline Shivering & 04 & 13.33 & 02 & 6.66 & 02 & 6.66 & 0.016 \\
\hline
\end{tabular}

Table 3. Side Effects And Complications During Study Period

Note: The percentage comparison is done out of 30 patients in each group and the group having lesser side-effect is considered better than the other two groups

\section{DISCUSSION}

Femoral nerve block results in sensory and motor blockade of the anterior part of thigh and articular branches of femur and knee joint.

Knee is mainly innervated by three nerves namely: Femoral nerve, Lateral cutaneous nerve and Sciatic nerve. In our study we used femoral nerve block along with Lateral femoral cutaneous nerve block in patients undergoing knee and above knee surgeries to study and compare the postoperative analgesic effects of $0.5 \%$ Ropivacaine and $0.5 \%$ Bupivacaine in patients whom surgeries were performed under spinal anaesthesia. Although these blocks can be performed by landmark technique alone but for better success rate, we used peripheral nerve stimulator (PNS) in this study. Tierney et $\mathrm{al}^{4}{ }^{4}$ Ozen $\mathrm{M}$ et $\mathrm{al}^{5}$ also used FNB and found effective in post-operative pain relief in knee and above knee surgeries.

In our study Demographic profile were comparable as regards to age and weight, although preponderance of male was observed in the study probably due to more outdoor movement of male in the society.

Time for onset of Analgesia:

In the non-randomised control trial study, the mean $( \pm$ SD) time for onset of analgesia was found to be $44 \pm 10.03$ seconds, $73.66 \pm 12.45$ seconds in Group R and Group B respectively. There was no analgesia up to 5 mins in Group $\mathrm{N}$ because we used normal saline for Femoral and Lateral cutaneous nerve block which has no local anaesthesia properties $(\mathrm{p}<0.000)$. This is due to the faster onset of action of Ropivacaine as compared to Bupivacaine. The results of our study are in accordance with Theodosiadis $\mathrm{P}$ et al ${ }^{6}$ in which the median onset time of block was significantly faster in those who received Ropivacaine than Bupivacaine (13 vs. 17.5 minutes, $\mathrm{p}<0.001$ ). Fanelli $\mathrm{G}$ et $\mathrm{al}^{7}$ showed that onset of sensory and motor blockade in Ropivacaine group was shorter than Bupivacaine group ( $\mathrm{p}=0.002)$.

\section{Duration of Analgesia}

The mean $( \pm \mathrm{SD})$ duration of analgesia was found to be $5.86 \pm$ $0.73,10.53 \pm 1.96$ and $7.06 \pm 1.01$ hours in Group N, Group R and Group B respectively. The duration of analgesia in control Group N (5.86 \pm 0.73 hours) was due to the effect of subarachnoid block, as we used normal saline to avoid the study bias. $(\mathrm{p}<0.000)$. These observations were supported by Patel $\mathrm{R}$ et $\mathrm{al}^{8}$ in which the total duration of postoperative analgesia in Group R was 7.83 \pm 0.98 hours and Group B was $6.33 \pm 0.76$ hours $(p<0.001)$. This is due to the differential blockade of nerve fibers by Ropivacaine thereby better differentiation in postoperative analgesia from Bupivacaine.

De Lima et $\mathrm{al}^{9}$ showed that using either $0.25 \%$ Ropivacaine or $0.25 \%$ Bupivacaine was useful for postoperative analgesia after TKR and ACL reconstruction for first 10 hours after spinal anaesthesia.

\section{Time for Rescue Analgesia}

We gave Injection Tramadol $2 \mathrm{mg}$ per $\mathrm{kg}$ diluted in $100 \mathrm{ml}$ Normal Saline once patient complained of pain (VAS $>3$ ) in the post-operative recovery area. In the present study the mean $( \pm$ SD) time for rescue analgesia was found to be $7.13 \pm$ 1.01 hours, $15.06 \pm 1.72$ hours, $11.33 \pm 1.52$ hours in Group $\mathrm{N}$, Group R and Group B respectively $(\mathrm{P}<0.000)$.

Our results are again similar to that of Patel $\mathrm{R}$ et al ${ }^{8}$ in which majority of patients in Group Ropivacaine were given rescue analgesia after 8 hours in post-operative period. Ozen $\mathrm{M}$ et $\mathrm{al}^{5}$ studied the effect of Ropivacaine in Femoral nerve block and found out that pain scores were significantly less in first 8 hours.

\section{Adverse Effects}

In our study we observed minimal side effects among the three study groups. The incidence of nausea \& vomiting, shivering, were higher in Group NS as compared to group R and group $B$ which could be due to the response of the neuroendocrine system of the body by releasing stress hormones in response to early onset of pain and discomfort. Various other studies such as Patel $\mathrm{R}$ et al, ${ }^{8}$ Fanelli $\mathrm{G}$ et $\mathrm{al},{ }^{7}$ Ozen $\mathrm{M}$ et $\mathrm{al}, 5$ also showed insignificant difference in the appearance of adverse effects.

\section{CONCLUSION}

$0.5 \%$ Ropivacaine at the dose of $15 \mathrm{~mL}$ and $8 \mathrm{~mL}$ used in Femoral Nerve Block and Lateral Cutaneous Nerve Block respectively provides early onset, prolonged duration of effect, better relief in post-operative pain with minimal adverse effect as compared to $0.5 \%$ Bupivacaine in similar dosage.

\section{REFERENCES}

[1] Grossi P, Urmey WF. Peripheral nerve block for anaesthesia and postoperative analgesia. Curr Opin Anaesthesiol 2003;16(5):493-501.

[2] Kulkarni A, Thatthe WS, Sai T. To know femoral nerve block (FNB) with $0.75 \%$ ropivacaine is aid to regional anesthesia (SAB) for femur and hip surgeries. Ind J App Res 2015;5(9):190-2. 


\section{Jemds.com}

[3] Kuthiala G, Chaudhary G. Ropivacaine: a review of its pharmacology and clinical use. Ind $J$ Anaesth 2011;55(2):104-10.

[4] Tienery E, Lewis G, Hurting JB, et al. Femoral nerve block with bupivacaine $0.25 \%$ percent for postopeative analgesia after open knee surgery. Can J Anaesth 1987;34(5):455-8.

[5] Ozen $\mathrm{M}$, Inan $\mathrm{N}$, Tumer $\mathrm{F}$, et al. The effect of 3-in-1 femoral nerve block with ropivacaine $0.375 \%$ on postoperative morphine consumption in elderly patients after total knee replacement surgery. Agri 2006;18(4):44-50.

[6] Theodosiadis P, Sachinis N, Goroszeniuk T, et al. Ropivacaine versus bupivacaine for 3 -in-1 block during total knee arthroplasty. J Orthop Surg (Hong Kong) 2013;21(3):300-4.

\section{Original Research Article}

[7] Fanelli G, Casati A, Beccaria P, et al. A double blind comparison of ropivacaine, bupivacaine and mepivacaine during sciatic and femoral nerve blockade. Anesth Analg 1998;87(3):597-600.

[8] Patel R, Patel D, Desal A, et al. To study analgesic effect of $0.25 \%$ bupivacaine Vs $0.25 \%$ ropivacaine in " 3 in 1 " femoral nerve block for knee surgeries. International J Research Medicine 2015;4(4):60-9.

[9] De Lima E Souza R, Correa $\mathrm{CH}$, Henriques MD, et al. Single- injection femoral nerve block with $0.25 \%$ ropivacaine or $0.25 \%$ bupivacaine for postoperative analgesia after total knee replacement or anterior cruciate ligament reconstruction. J Clin Anesth 2008;20(7):521-7. 